\title{
Changes in fibroblast growth factor 9 mRNA in granulosa and theca cells during ovarian follicular growth in dairy cattle
}

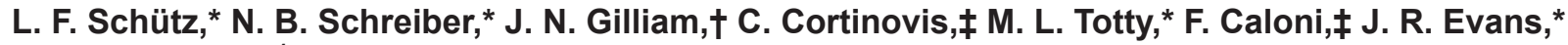 \\ and L. J. Spicer*1 \\ *Department of Animal Science, and \\ †Department of Veterinary Clinical Sciences, Oklahoma State University, Stillwater 74078 \\ fUniversità degli Studi di Milano, Department of Health, Animal Science and Food Safety, Via Celoria 10, 20133 Milan, Italy
}

\section{ABSTRACT}

Fibroblast growth factor 9 (FGF9) has been suggested to act as an antidifferentiation factor in cattle by reducing steroidogenesis and increasing cell proliferation in granulosa (GC) and theca (TC) cells. The objective of this study was to characterize FGF9 mRNA abundance in GC and TC during development of dominant follicles in dairy cattle. Estrous cycles of nonlactating dairy cattle were synchronized, and ovaries were collected on either d 3 to $4(\mathrm{n}=8)$ or 5 to $6(\mathrm{n}=8)$ postovulation for GC and TC RNA extraction from small $(1-5 \mathrm{~mm})$, medium $(5.1-8 \mathrm{~mm})$, and large (8.1-18 mm) follicles for PCR analysis. The FGF9 mRNA abundance was greater in GC than in TC. In GC, FGF9 mRNA abundance was greater in small, medium, and large estrogen-inactive [i.e., concentrations of estradiol (E2) < progesterone (P4)] follicles than in large E2-active (i.e., concentrations of E2 > $\mathrm{P} 4$ ) follicles at both early (d 3-4) and late (d 5-6) growing phases of first dominant follicle. Abundance of FGF9 mRNA increased in medium-sized follicles from early to late growing phase of the dominant follicle. In TC, FGF9 mRNA abundance was greater in large E2-inactive follicles than in large E2-active follicles on d 3 to 4 postovulation; no significant differences in TC FGF9 mRNA existed among follicle types on d 5 to 6 postovulation. Correlations among levels of follicular fluid hormones and FGF9 mRNA levels revealed significant negative correlations between GC FGF9 mRNA abundance and follicular fluid E2 $(\mathrm{r}=-0.68)$, free IGF-1 ( $\mathrm{r}=-0.63)$, and E2-to-P4 ratio $(\mathrm{r}=-0.58)$. In summary, abundance of FGF9 mRNA in GC and TC increases in medium-sized follicles during development of dominant follicles and is less in dominant E2-active than subordinate E2-inactive follicles, suggesting that

\footnotetext{
Received November 19, 2015.

Accepted July 27, 2016.

${ }^{1}$ Corresponding author: leon.spicer@okstate.edu
}

FGF9 signaling could contribute to normal follicle development and steroidogenesis in dairy cattle.

Key words: fibroblast growth factor-9 (FGF9), theca cell, granulosa cell, follicle growth

\section{INTRODUCTION}

Fibroblast growth factors (FGF) constitute a large family of polypeptide growth factors present in both vertebrates and invertebrates (Ornitz and Itoh, 2001). These growth factors and their receptors are distributed in various tissues and regulate development, metabolism, and disease through intracrine, paracrine, and endocrine mechanisms of action (Itoh and Ornitz, 2011). The FGF family members have also been identified to play important roles in the reproduction of mammals including the human, caprine, ovine, bovine and murine species (for review see Chaves et al., 2012). To date, FGF1, FGF2, FGF7-9, FGF10, FGF17, and FGF18 have been identified in the ovary of humans (Oron et al., 2012), rodents (Drummond et al., 2007), or domestic animals (Berisha et al., 2004; Machado et al., 2009; Portela et al., 2010; Schreiber et al., 2012). Functions of FGF members in the ovary include regulation of granulosa cell (GC) steroidogenesis of cattle (Vernon and Spicer, 1994; Schreiber and Spicer, 2012) and pigs (Evans et al., 2014), regulation of GC apoptosis and survival in rats (Tilly et al., 1992; Peluso et al., 2001) and cattle (Portela et al., 2010; Jiang and Price, 2012), control of bovine GC proliferation and differentiation (Berisha et al., 2004; Schreiber and Spicer, 2012), oocyte maturation in rats (LaPolt et al., 1990) and cattle (Cho et al., 2008), and luteal development in cattle (Gabler et al., 2004; Woad et al., 2012).

In cattle, abundance of FGF9 mRNA was first observed to be downregulated in GC of cystic follicles compared with noncystic follicles in a microarray study, indicating that FGF9 may play a role in bovine follicular development (Grado-Ahuir et al., 2011). Subsequently, abundance of FGF9 mRNA was found to be greater in 
GC than in theca cells (TC) and greater in both GC and TC in small follicles (i.e., 1-5 mm) in comparison to large (i.e., $\geq 8 \mathrm{~mm}$ ) follicles (Schreiber et al., 2012). Hormones known to be involved in follicular development (e.g., IGF-1) also regulate $F G F 9$ mRNA in both GC (Schreiber and Spicer, 2012) and TC (Schreiber et al., 2012). Furthermore, FGF9 treatment stimulated bovine GC and TC proliferation while downregulating hormone-stimulated steroidogenesis and steroidogenic enzyme gene expression, suggesting a role for FGF9 as an antidifferentiation factor regulating folliculogenesis (Schreiber and Spicer, 2012; Schreiber et al., 2012). Increased free IGF-1 is thought to amplify FSH-induced estradiol (E2) production in the developing dominant follicle of cattle (Spicer, 2004). However, whether endogenous production of FGF9 by ovarian follicular cells changes during selection of dominant follicles in monotocous mammals such as cattle is still unknown. We hypothesized that FGF9 mRNA decreases as follicles grow and differentiate. Therefore, the objective of the current study was to determine if abundance of FGF9 mRNA in GC and TC changes during growth of first-wave dominant follicles in dairy cattle exhibiting regular estrous cycles.

\section{MATERIALS AND METHODS}

\section{In Vivo Experiment: Animals and Experimental Design}

Nonlactating Holstein cows $(\mathrm{n}=18)$ were used for this experiment as previously described (Dentis et al., 2016). Briefly, estrous cycles were synchronized using 2 injections (im) of $\mathrm{PGF}_{2 \alpha}$ (Lutalyse, $25 \mathrm{mg}$, Pharmacia \& Upjohn Co., Kalamazoo, MI) with an interval of 11 d. From the first injection of $\mathrm{PGF}_{2 \alpha}$ to the occurrence of ovulation after the second injection, follicle development was monitored daily via ultrasonography using an Aloka 500V (Aloka Co., Tokyo, Japan) with a 7.5-MHz probe. Following ovulation, cows continued to be monitored with daily ultrasonography and were assigned to be ovariectomized either at d 3 to 4 (early growing phase of the first dominant follicle; $\mathrm{n}=9$ cows) or 5 to 6 (late growing phase of the first dominant follicle; $\mathrm{n}=$ 9 cows). From the 18 cows used in the synchronization program, 2 failed (1 from d 3 and 1 from d 6 groups) to ovulate and were excluded from this experiment. After each ovariectomy, ovaries were put on ice and transported to the laboratory where diameters of all follicles $\geq 5 \mathrm{~mm}$ (surface diameter) in diameter were recorded, the numbers of all follicles $\geq 1 \mathrm{~mm}$ in diameter on the ovarian surface determined, and ovarian tissue and fluid collected (Dentis et al., 2016). The animal experimentation described in this report was approved by the Oklahoma State University Institutional Animal Care and Use Committee.

\section{Cell and Follicular Fluid Collection}

For GC sample collection, follicles were categorized by surface diameter as small $(1-5 \mathrm{~mm})$, medium (5.1-8 $\mathrm{mm})$, or large $(8.1-18 \mathrm{~mm})$; TC samples were collected from only medium and large follicles. Follicular fluid (FFL) from medium and large follicles was aspirated individually and centrifuged $\left(200 \times g\right.$ at $4^{\circ} \mathrm{C}$ for $\left.8 \mathrm{~min}\right)$ to obtain GC; FFL from small follicles was pooled within each ovary and then centrifuged to obtain GC as previously described (Stewart et al., 1996; Dentis et al., 2016). After centrifugation, FFL was aspirated and stored at $-20^{\circ} \mathrm{C}$ for subsequent RIA. After collection of FFL, each medium and large follicle was bisected in situ, the inner wall was scraped, rinsed with Ham's F-12 (Sigma-Aldrich, St. Louis, MO) to remove any remaining $\mathrm{GC}$, and these $\mathrm{GC}$ were combined with GC collected from FFL as previously described (Schreiber and Spicer, 2012; Dentis et al., 2016). The GC collected from small follicles were kept separate for each ovary; GC were lysed in $0.5 \mathrm{~mL}$ of TRIzol reagent (Life Technologies Inc., Grand Island, NY) and stored frozen at $-80^{\circ} \mathrm{C}$ until RNA extraction. The TC were dissected from the bisected follicles and placed in $0.75 \mathrm{~mL}$ of TRIzol reagent (Life Technologies Inc.) and homogenized for 2 to $3 \mathrm{~min}$ on ice using the Omni TH tissue homogenizer (Omni International Inc., Marietta, GA) with Omni Tip disposable generator probes as previously described (Aad et al., 2012, 2013).

\section{In Vitro Experiments}

These experiments were designed to test the effects of E2 and dihydrotestosterone (DHT) on FGF9 mRNA abundance in GC and TC. To isolate GC, follicular fluid was aspirated from small (1-5 mm) follicles as previously described (Spicer, 1998; Lagaly et al., 2008). To isolate TC, large follicles were bisected with a scalpel after aspiration of FFL, attached GC were separated from theca interna via blunt dissection, and theca interna tissue was removed from the follicle wall and enzymatically digested in $10 \mathrm{~mL}$ of medium on a rocking platform for $1 \mathrm{~h}$ at $37^{\circ} \mathrm{C}$ as previously described (Stewart et al., 1995; Lagaly et al., 2008; Schreiber et al., 2012). Nondigested thecal tissue was removed via a sterile syringe filter holder with metal screen of 149- $\mu \mathrm{m}$ mesh (Gelman Sciences, Ann Arbor, MI). The $\mathrm{TC}$ were centrifuged at $50 \times g$ for $8 \mathrm{~min}$ at $4^{\circ} \mathrm{C}$, the pellets were washed twice in serum-free medium (1:1 
Dulbecco's modified eagles medium and F12 with 38.5 $\mathrm{m} M$ sodium bicarbonate, $0.12 \mathrm{~m} M$ gentamicin, and 2.0 $\mathrm{m} M$ glutamine; Sigma-Aldrich) and then resuspended in serum-free medium with enzymes (collagenase and DNase at 1.25 and $0.5 \mathrm{mg} / \mathrm{mL}$; Sigma-Aldrich) to prevent clumping, as previously described (Lagaly et al., 2008; Schreiber et al., 2012).

Viability of GC and TC used for cell culture was determined by trypan blue exclusion method on a $0.1-\mathrm{mm}$ deep hemacytometer (American Optical Corp., Buffalo, $\mathrm{NY}$ ), and averaged $28.1 \pm 3.0$ and $94.8 \pm 2.4 \%$, respectively. Approximately $3.0 \times 10^{5}$ viable cells/well were plated on 24-well Falcon multi-well plates (No. 3047; Becton Dickinson, Lincoln Park, NJ), with $1 \mathrm{~mL}$ of medium/well, and cultured (at $38.5^{\circ} \mathrm{C}$ with $5 \% \mathrm{CO}_{2}$ and $95 \%$ air) in 10\% fetal calf serum (Equitech-Bio Inc., Kerrville, TX) for the first $48 \mathrm{~h}$ with medium changed every $24 \mathrm{~h}$. Cells were then washed twice with $0.5 \mathrm{~mL}$ of serum-free medium and 3 treatments were applied as follows: control, E2 (300 ng/mL; Sigma-Aldrich), and DHT (300 ng/mL; Sigma-Aldrich). Doses of steroids were based on previous studies (Spicer and Hammond, 1988; Spicer, 2005). After 24 h of treatment, cells were lysed in TRIzol reagent (Life Technologies Inc.) and extracted for RNA.

\section{RNA Extraction and Quantitative PCR}

The RNA was extracted from GC and TC as described previously (Lagaly et al., 2008; Dentis et al., 2016). Samples of RNA were solubilized in diethylpyrocarbonate-treated water (Life Technologies Inc.), quantified at $260 \mathrm{~nm}$ using a NanoDrop ND-1000 spectrophotometer (NanoDrop Technologies Inc., Wilmington, DE), and stored at $-80^{\circ} \mathrm{C}$.

The FGF9 primers and probe (supplied as $5^{\prime}$ FAM reporter dye and a $3^{\prime}$ TAMRA quencher dye; TaqMan TAMARA; Applied Biosystems Inc., Foster City, CA) for quantitative PCR were designed using Primer Express software (Foster City, CA) as previously reported (Grado-Ahuir et al., 2011; Schreiber and Spicer, 2012). The FGF9 mRNA (697 bp; accession NM_001245926.1) forward primer was constructed between bp 387 and 408 with a melting temperature $(\mathbf{T m})$ of $58^{\circ} \mathrm{C}$ and a sequence of 5'-TCTACCTCGGCATGAATGAGAA-3'. The reverse FGF9 mRNA primer was constructed between bp 476 and 497 with a $\mathrm{Tm}$ of $57^{\circ} \mathrm{C}$ and a sequence of 5'-TGGAGGAGTACGTGTTGTACCA-3' The FGF9 mRNA probe was constructed between bp 421 and 444 with a $\mathrm{Tm}$ of $66^{\circ} \mathrm{C}$ and a sequence of 5'-TGGATCGGAAAAACTCACGCAAGA-3'. Relative mRNA abundance of target genes was quantified using fluorescent single-step quantitative PCR using an
ABI Prism 7500 sequence detection system (Applied Biosystems Inc.). Target gene expression was normalized to constitutively expressed $18 \mathrm{~S}$ ribosomal RNA (18S rRNA; supplied as a VIC probe; TaqMan Ribosomal RNA Control Reagent, Applied Biosystems Inc.), and relative quantity of FGF9 mRNA was expressed as $2^{-\Delta \Delta \mathrm{Ct}}$ using the relative comparative threshold cycle (Ct) method as previously described (Livak and Schmittgen, 2001; Lagaly et al., 2008).

\section{FFL Hormone RIA and ELISA}

To determine FFL concentrations of progesterone (P4) and E2, RIA were performed as previously described (Stewart et al., 1996; Dentis et al., 2016). All samples were run in 1 assay for each of the steroid RIA. Progesterone intra-assay coefficient of variation averaged $11.6 \%$, whereas E2 intra-assay coefficient of variation averaged $10.6 \%$.

Concentrations of free IGF-1 in FFL were determined in a subset of samples via a free IGF-1 ELISA kit (R\&D Systems, Minneapolis, MN) according to the manufacturer's protocol similar to that previously described (Santiago et al., 2005; Spicer et al., 2005). If sample values were below the limit of detection of the assay, a $0.2 \mathrm{ng} / \mathrm{mL}$ value was assigned to that sample. All samples were quantified in 1 assay and the intraassay coefficient of variation averaged $6.9 \%$.

\section{Statistical Analyses}

The analysis of data aimed to determine if FGF9 mRNA abundance changes in GC and TC during different periods of follicular development and to detect its relationship with steroidogenesis. Data were analyzed via factorial ANOVA with the general linear models procedure of SAS for Windows (ver. 9.2, SAS Institute Inc., Cary, NC) and are presented as the least squares means $( \pm$ SEM) of measurements. Main factors were days postovulation (early, d 3-4, and late, d 5-6, growing phase of the first dominant follicle), follicle status $(\mathrm{n}=4)$ based on size (small, medium, or large in the case of GC, and medium or large in the case of TC) and follicle estrogenic status [E2-active: E2 > P4 concentrations (EA), or E2-inactive: E2 $<$ P4 concentrations (EI)], and their various interactions. Some cows had 2 EA follicles on d 3 to 4 whereas some cows had no EA follicles on d 5 to 6 . Also, if FFL samples were lost during collection, then E2 status could not be determined and gene expression data were not included in the analysis. For analysis of E2, P4, and free IGF-1 concentrations in the subset $(\mathrm{n}=32)$ of FFL samples, main factors were days postovulation (early, d 3-4, and 
late, d 5-6, growing phase of the first dominant follicle), follicle status $(\mathrm{n}=3$ ) based on size (small EI, large EA, or large EI), and their various interaction. To correct for heterogeneity of variance, abundance of FGF9 mRNA was analyzed after transformation to natural $\log (x+1)$. Mean differences were determined by Fisher's protected least significant differences test (Ott, 1977) only if significant main effects in the ANOVA were detected. To evaluate the relationships among variables measured, Pearson correlation coefficients were generated using CORR procedure of SAS (SAS Institute). Significance was declared at $P<0.05$.

\section{RESULTS}

\section{GC FGF9 mRNA Abundance}

Averaged across follicle size groups, quantitative PCR results indicated that FGF9 mRNA abundance in $\mathrm{GC}$ was 6.2 fold greater $(P<0.05)$ than in TC, and that GC FGF9 mRNA abundance increased 2.9 fold $(P<0.05)$ from the early (d $3-4$ postovulation) to late (d 5-6 postovulation) growing phase of the first dominant follicle (49 \pm 7 and $145 \pm 46$, respectively). Abundance of $F G F 9$ mRNA was greater $(P<0.01)$ in large, medium, and small EI $(\mathrm{E} 2 / \mathrm{P} 4$ ratio $<1)$ than in large EA (E2/P4 ratio $>1)$ follicles at both early $(19,27$, and 18 fold greater, respectively) and late (35, 77 , and 32 fold greater, respectively) growing phases of first dominant follicle (Figure 1A). Also, when EI follicles of same size were compared at different days postovulation, FGF9 mRNA abundance increased 3.7 fold $(P<0.01)$ in medium-sized follicles from early to late growing phase of the first dominant follicle, whereas no significant differences were detected between large or small EI follicles (Figure 1A). Abundance of FGF9 mRNA in GC was 2.2 fold greater $(P<0.01)$ in EI medium- and small-sized follicles than in EI large-sized follicles at late growing phase (d 5-6) of the first dominant follicle, with no significant differences observed between other sizes at this phase or between any of the EI follicle sizes at d 3 to 4 postovulation (Figure 1A). Averaged across days, FGF9 mRNA abundance in GC was several-fold greater $(P<0.01)$ in large $(70.6 \pm$ 14.1), medium $(179.6 \pm 38.6)$, and small $(90.5 \pm 21.1)$ EI than in large EA follicles $(5.1 \pm 1.0)$.

\section{TC FGF9 mRNA Abundance}

In contrast to what was observed in GC, averaged across follicle size groups there was a tendency $(P=$ $0.05)$ for TC $F G F 9$ mRNA abundance to be greater in early $(2.7 \pm 3.1)$ than in late $(1.6 \pm 0.7)$ growing
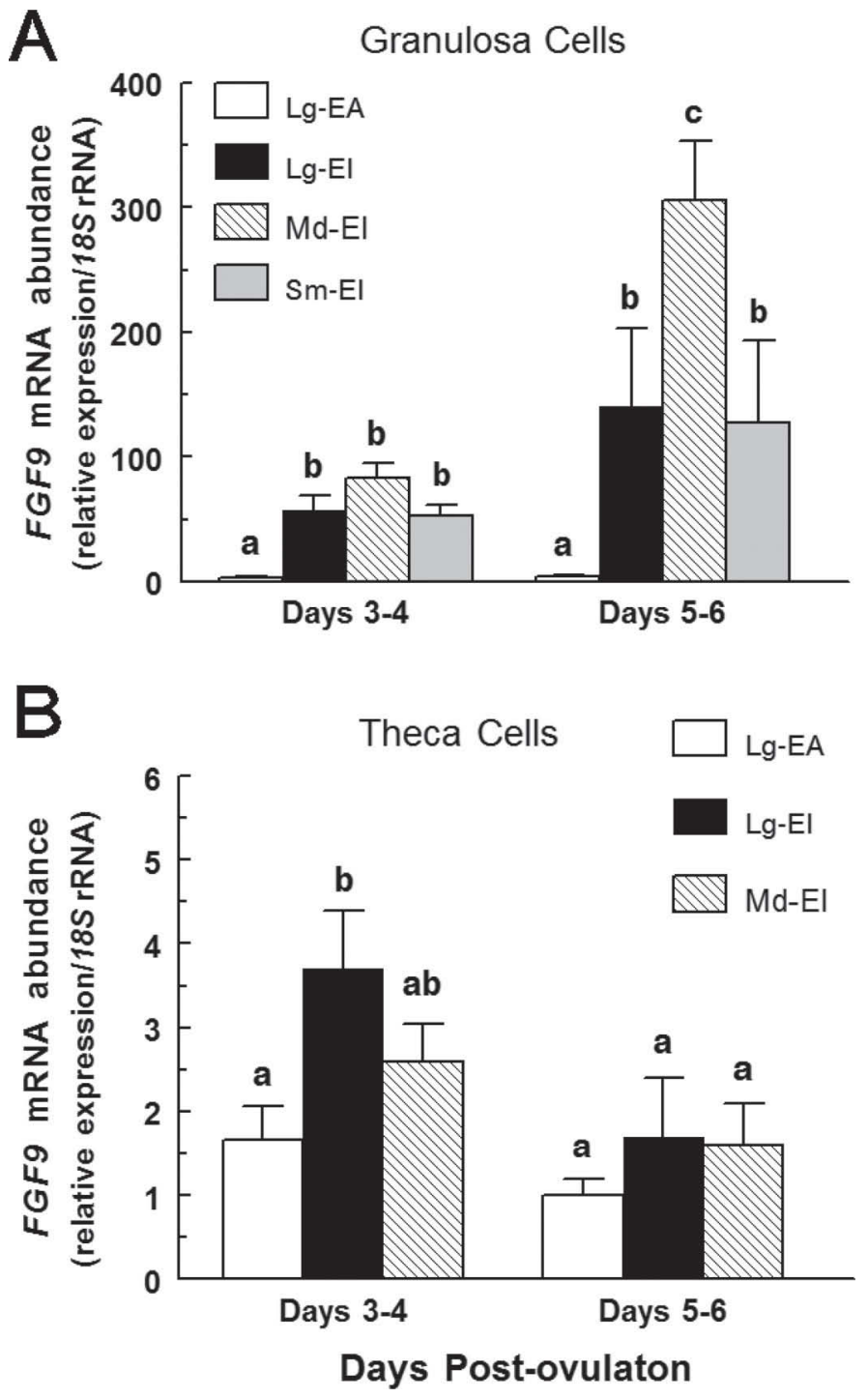

Figure 1. Abundance of FGF9 mRNA in granulosa and theca cells during follicular growth. (A) Effects of follicular size ( $\mathrm{Lg}=$ large; $\mathrm{Md}$ $=$ medium $; \mathrm{Sm}=$ small $)$ and estradiol status $(\mathrm{EA}=$ estrogen active; $\mathrm{EI}=$ estrogen inactive) on FGF9 mRNA in bovine granulosa cells on different days postovulation. Means without a common letter $(\mathrm{a}-\mathrm{c})$ differ $(P<0.05) ; \mathrm{n}=10,16,36$, and 16 for Lg-EA, Lg-EI, Md-EI, and Sm-EI, respectively, for d 3 to $4 ; \mathrm{n}=5,17,27$, and 14 for $\mathrm{Lg}$ EA, Lg-EI, Md-EI, and Sm-EI, respectively, for d 5 to 6. (B) Effect of follicular size and estradiol status on abundance of FGF9 mRNA in bovine theca cells on different days postovulation. Means without a common letter $(\mathrm{a}, \mathrm{b})$ differ $(P<0.05)$; $\mathrm{n}=9,13$, and 28 for Lg-EA, Lg$\mathrm{EI}$, and Md-EI, respectively, for d 3 to $4 ; \mathrm{n}=4,11$, and 23 for $\mathrm{Lg}$-EA, Lg-EI, and Md-EI, respectively, for d 5 to 6 . Values are normalized to constitutively expressed $18 \mathrm{~S}$ ribosomal RNA and are LSM \pm SEM.

phase of the first dominant follicle. Abundance of FGF9 mRNA in TC was 2.2 fold greater $(P<0.05)$ in large subordinate EI follicles than in large dominant EA follicles on d 3 to 4 postovulation (Figure 1B). No other significant differences were detected between 
subordinate EI and large dominant EA follicles on d 5 to 6 postovulation, or between large and medium EI follicles. Abundance of FGF9 mRNA in TC decreased in large subordinate EI follicles between d 3 to 4 and 5 to 6 postovulation, whereas no significant changes were observed in the other 2 groups of follicles (Figure 1B).

\section{Follicle Size, E2, P4, and Free IGF-1 Concentrations in FFL}

Follicle size and steroid concentrations in FFL have been reported for this study (Dentis et al., 2016). Briefly, diameter of large dominant EA, large subordinate EI, and medium EI follicles averaged $12.9 \pm 0.5,9.48$ \pm 0.36 , and $6.37 \pm 0.23 \mathrm{~mm}$, respectively. Concentrations of E2 in large dominant EA, large subordinate EI, medium EI, and small EI follicles averaged 186.5 $\pm 29.5,8.45 \pm 3.7,2.3 \pm 0.8$, and $2.0 \pm 0.2 \mathrm{ng} / \mathrm{mL}$, respectively. Concentrations of $\mathrm{P} 4$ did not differ $(P>$ $0.10)$ among follicle groups and ranged between $61 \pm 7$ and $236 \pm 42 \mathrm{ng} / \mathrm{mL}$.

In a subset of these samples $(\mathrm{n}=32)$, FFL concentrations of E2, P4, and free IGF-1 in large dominant EA, large subordinate EI, and small EI follicles are shown in Figure 2. Day or its interaction did not significantly affect E2, P4, or free IGF-1 concentrations, thus data were pooled across days; large dominant EA follicles had greater $(P<0.05)$ free IGF-1 (Figure $2 \mathrm{~A})$ and E2 (Figure $2 \mathrm{~B})$ but tended to have less $(P<0.10)$ P4 (Figure 2B) than large EI and small EI follicles. Concentrations of free IGF-1, E2, and P4 in FFL of large EI and small EI follicles did not differ $(P>0.10)$.

\section{Correlations Between FFL Levels of Hormones and FGF9 mRNA Relative Abundance}

Negative correlations existed between GC FGF9 mRNA abundance and FFL E2 $(\mathrm{r}=-0.68, P<0.001$; Figure 3$)$ and E2-to-P4 ratio $(\mathrm{r}=-0.58, P<0.001$; $\mathrm{n}=140)$. In contrast, a weak positive correlation ( $\mathrm{r}$ $=0.18, P<0.05)$ existed between GC FGF9 mRNA abundance and FFL P4. No significant correlation was observed between TC FGF9 mRNA abundance and FFL P4 ( $\mathrm{r}=0.06, P>0.50)$, but weak negative correlations existed between TC FGF9 mRNA abundance and FFL E2 $(\mathrm{r}=-0.26, P<0.05)$ and E2-to-P4 ratio $(\mathrm{r}=-0.22, P=0.05 ; \mathrm{n}=88)$. Concentrations of free IGF-1 in FFL and GC FGF9 mRNA abundance were negatively correlated $(\mathrm{r}=-0.63, P<0.001 ; \mathrm{n}=32)$, whereas free IGF-1 concentrations and E2 concentrations in FFL were positively correlated $(\mathrm{r}=0.85, P<$ 0.001). No significant correlation existed between concentrations of $\mathrm{P} 4$ and free IGF- $1(\mathrm{r}=-0.19, P>0.10)$
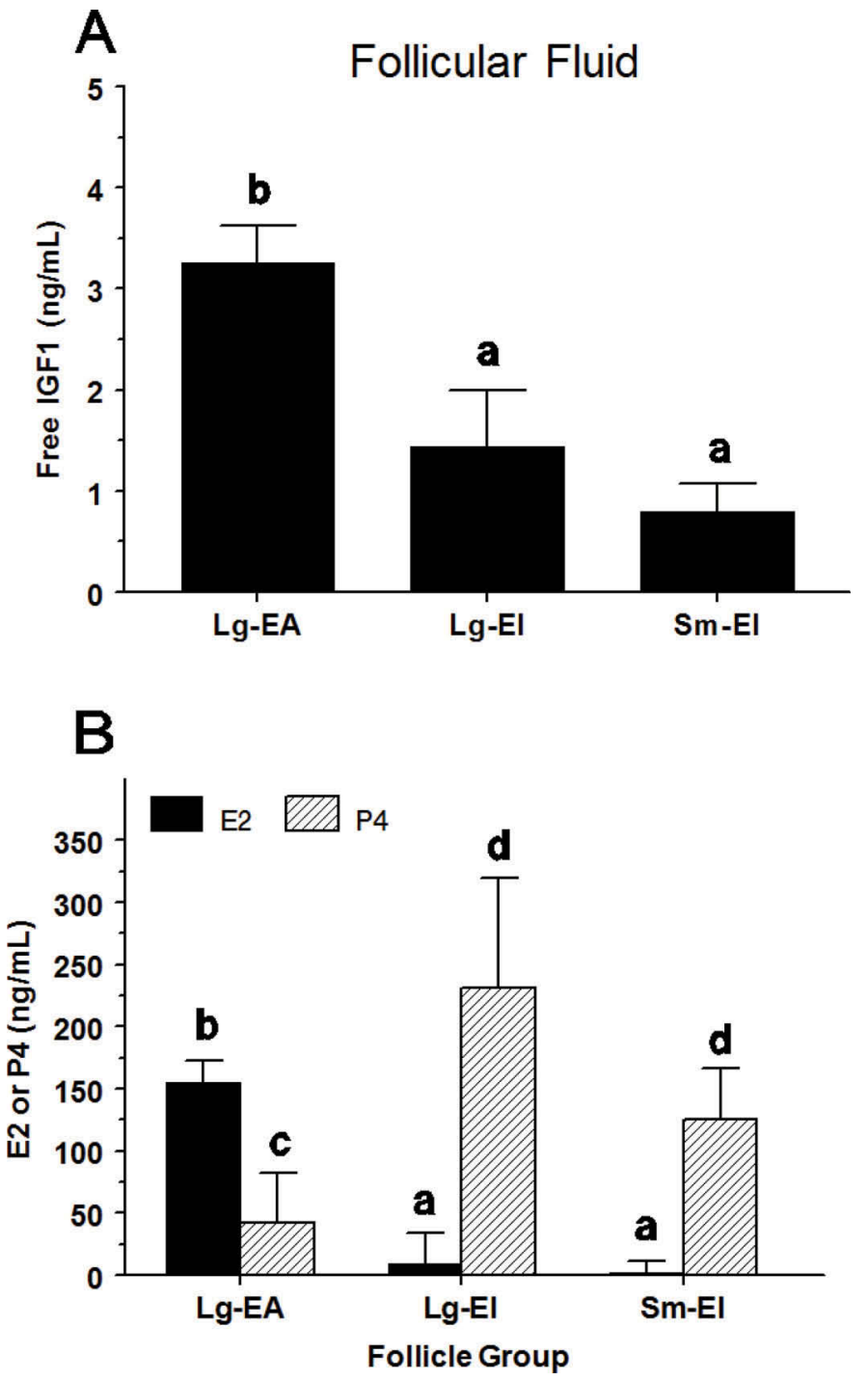

Figure 2. Effects of follicular size $(\mathrm{Lg}=$ large; $\mathrm{Sm}=$ small $)$ and estradiol (E2) status (EA = estrogen active; EI = estrogen inactive) on concentrations of free IGF-1 (A) or E2 and progesterone (P4; B) in follicular fluid. Means ( $\mathrm{n}=6-18$ follicles per group) without a common letter $(\mathrm{a}, \mathrm{b})$ differ $(P<0.05)$; means $(\mathrm{n}=6-17$ follicles per group) without a common letter $(\mathrm{c}, \mathrm{d}) \operatorname{differ}(P<0.05)$. Values are $\mathrm{LSM} \pm \mathrm{SEM}$.

in FFL. The E2-to-P4 ratio was positively correlated with free IGF-1 $(\mathrm{r}=0.63, P<0.001)$.

\section{In Vitro Experiment: Effects of E2 and DHT on FGF9 mRNA Abundance in TC}

Treatment of TC with DHT decreased $(P<0.05)$ FGF9 mRNA abundance by $65 \%$, whereas E2 treatment tended to decrease $(P<0.10)$ TC FGF9 mRNA abundance by $42 \%$ (Figure $4 \mathrm{~A})$. 


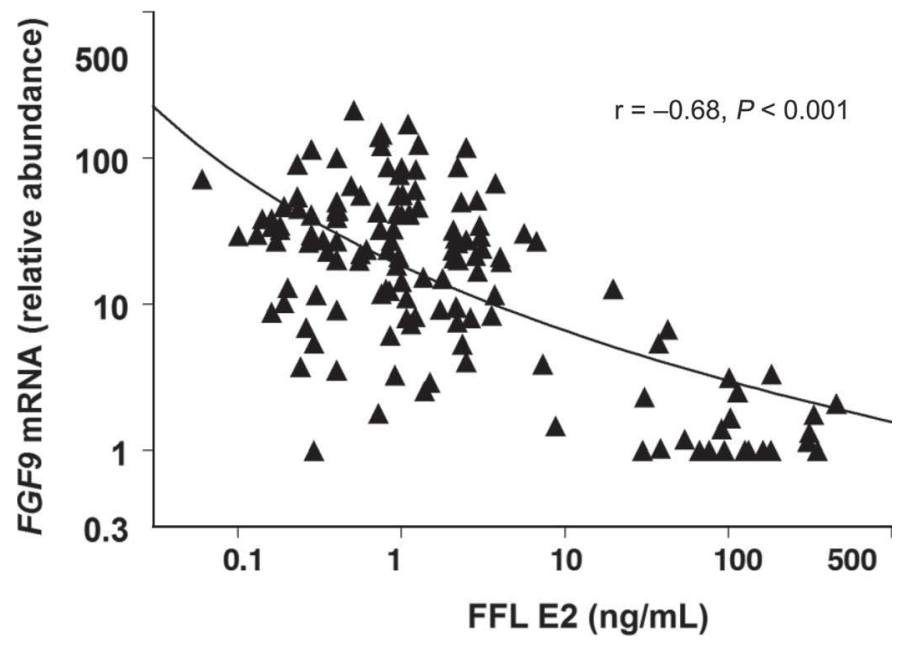

Figure 3. Correlation between FGF9 mRNA abundance in granulosa cells and concentrations of estradiol (E2) in follicular fluid (FFL). The relationship between $F G F 9$ mRNA abundance and concentrations of E2 in FFL collected between d 3 and 6 postovulation is represented by the fitted $(\log )$ line $(-)$.

\section{In Vitro Experiment: Effects of E2 and DHT on FGF9 mRNA Abundance in GC}

Treatment of small-follicle GC with E2 increased $(P$ $<0.05)$ FGF9 mRNA abundance by 5.8 fold, whereas DHT treatment increased $(P<0.05)$ FGF9 mRNA abundance in small-follicle GC by 8.2 fold (Figure 4B).

\section{DISCUSSION}

The FGF9 has been characterized as an antidifferentiation factor in folliculogenesis of cattle, stimulating both GC and TC proliferation while inhibiting steroidogenesis (Schreiber and Spicer, 2012; Schreiber et al., 2012). In the present study, we report for the first time that FGF9 mRNA abundance in GC and TC changes according to E2 activity and size of follicles and also during follicle development in cattle.

In the present study, follicles were collected at specific days of a synchronized cycle during the first follicular wave and thus represent a well-defined physiologic model. Consistent with what is expected from a factor that stimulates cells to proliferate while inhibiting their differentiation by decreasing E2 production (as described in Schreiber and Spicer, 2012; Figure 5), the abundance of FGF9 mRNA in GC was less in large dominant EA follicles at early and late growing phases of the first follicular wave than in subordinate EI follicles of various sizes, indicating that FGF9 production likely decreases as the follicle becomes dominant and increased steroidogenesis is required for its further differentiation. In support of this latter suggestion, FFL
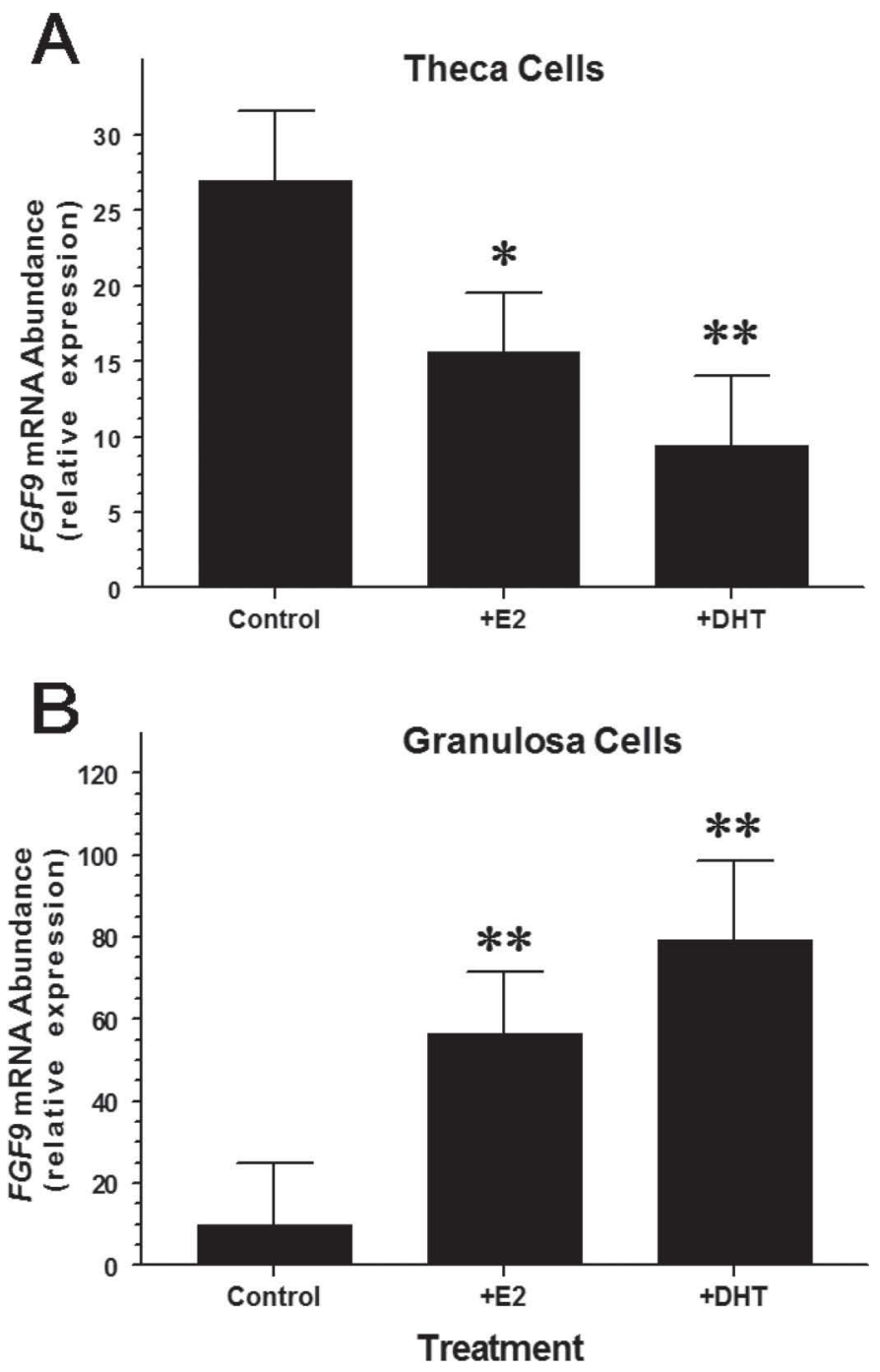

Figure 4. In vitro effects of estradiol (E2) and dihydrotestosterone (DHT) on abundance of FGF9 mRNA expression in theca cells of experiment 4 (A) and granulosa cells of experiment 5 (B). Theca and granulosa cells were isolated and cultured in $10 \%$ fetal calf serum and then treated in serum-free medium with $300 \mathrm{ng} / \mathrm{mL}$ of either E2 or DHT for $24 \mathrm{~h}$. Values (LSM \pm SEM) are normalized to constitutively expressed 18S ribosomal RNA. ${ }^{*} P<0.05,{ }^{* *} P<0.10$.

E2 levels and E2-to-P4 ratio were negatively correlated with FGF9 mRNA abundance in GC and TC in the present study. Results from our in vitro studies indicate that increased E2 and androgens may directly inhibit FGF9 mRNA expression in large-follicle TC, but stimulate FGF9 mRNA in small-follicle GC. Because E2 is critical for GC differentiation (Knecht et al., 1985), it is likely that FGF9 would be acting to prevent premature follicular selection, with an early increase of E2 production in small follicles stimulating an increase in FGF9 to prevent E2 concentrations from rising before the time of selection has come. This stimulation of FGF9 
mRNA by E2 and DHT may also be one mechanism whereby large follicles suppress differentiation of small follicles. It is possible that large-follicle GC respond differently to E2 and DHT than do small-follicle GC, and this may be why in vivo, diethylstilbesterol treatment had no significant effect on whole ovarian (i.e., a mix of small and large follicles and TC and GC) FGF9 mRNA expression in rats (Drummond et al., 2007). The absence of any change in FFL P4 levels during significant changes in both GC and TC FGF9 mRNA indicates that $\mathrm{P} 4$ likely does not regulate $F G F 9$ mRNA. Also, in the present study, GC FGF9 mRNA increased in medium EI follicles as the follicular wave advanced from early to late in the growing phase of the first dominant follicle, resulting in a greater abundance of FGF9 mRNA in medium- than in large-sized follicles at $\mathrm{d} 5$ to 6 postovulation. Perhaps FGF9 is important to ensure that only one follicle will differentiate and dominate at the end of the first follicular wave in a monovulatory species such as cattle. Previous studies in cattle report a greater abundance of FGF18 mRNA in GC and TC of subordinate versus dominant follicles (Portela et al., 2010), and a greater abundance of FGF2 mRNA (Berisha et al., 2004) and FGF10 mRNA (Buratini et al., 2007) in TC of estrogenic versus nonestrogenic antral follicles. In contrast, $F G F 1$ and $F G F$ r mRNA abundance in GC and TC do not change during follicular development in cattle (Berisha et al., 2004) or pigs (Schams et al., 2009). Collectively, the previous and present studies indicate different developmental control of the various FGF in GC and TC of follicles during folliculogenesis.

As mentioned, E2 and DHT increased FGF9 mRNA abundance in small-follicle GC, suggesting that one or more hormones or intraovarian factors other than E2 or DHT are the cause for lower abundance of FGF9 mRNA in GC of large dominant EA follicles. One of these other intraovarian factors may be IGF-1 because IGF-1 decreases abundance of $F G F 9$ mRNA in GC from both small and large follicles (Schreiber and Spicer, 2012); as observed in the present and previous studies, concentrations of free IGF-1 in FFL increase in early dominant follicles (Fortune et al., 2001; Spicer, 2004) as well as in preovulatory dominant follicles (Santiago et al., 2005) in cattle. Importantly, dairy cows in positive energy balance exhibit increased systemic IGF-1 concentrations versus cows in negative energy balance (Spicer et al., 1990), which could affect intraovarian concentrations of IGF-1 (Spicer et al., 1992) and, thus, ovarian function. In addition, free IGF-1 concentrations in FFL and FGF9 mRNA abundance in GC were negatively correlated in the present study. Thus, we hypothesized that increases in free IGF1 during dominant follicle development (Fortune et al., 2001; Spicer, 2004)

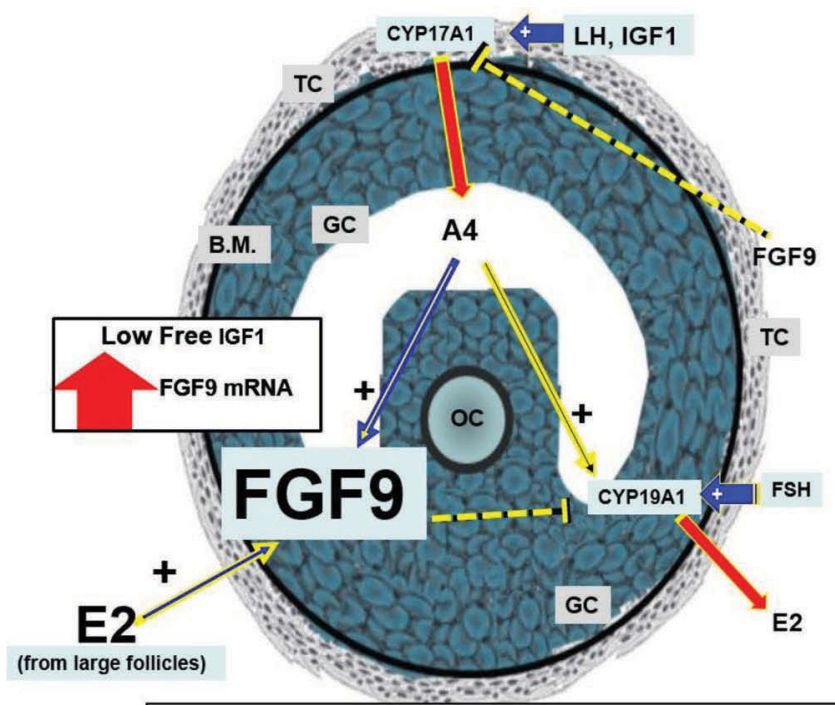

FGF9 production in small follicles

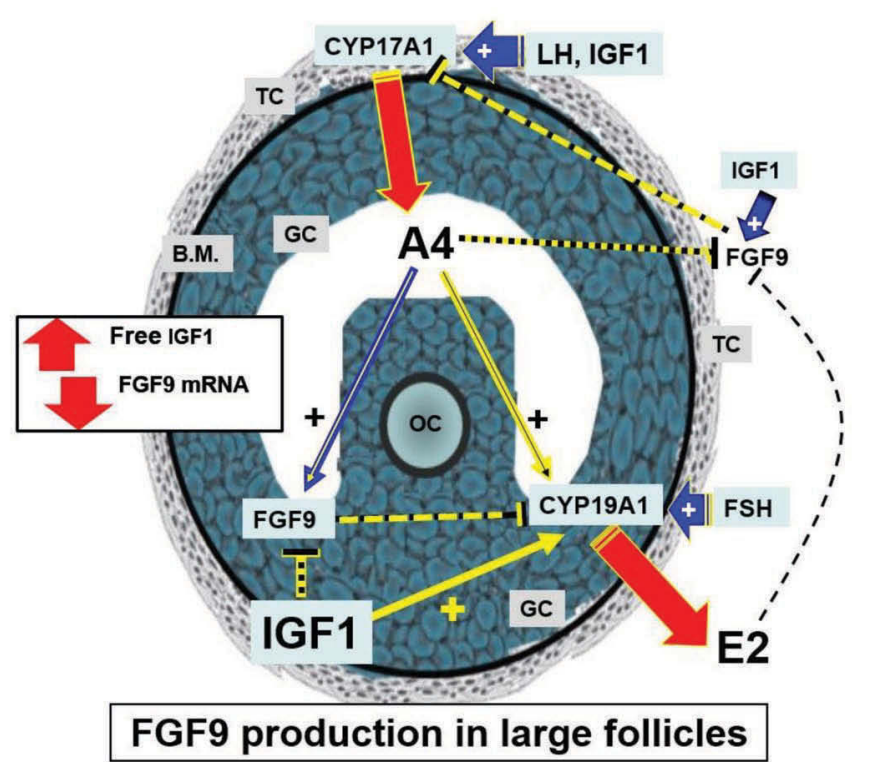

Figure 5. Schematic model summarizing the hormonal regulation of FGF9 production by granulosa cells (GC) and theca cells (TC) in small (top panel) and large (bottom panel) follicles. Dashed line with $\mathrm{T}$ at end indicates inhibitory effects; a hormone by an arrow with a "+" indicates stimulatory effects; a hormone by an arrow with a "-" indicates inhibitory effects. The IGF-1, FSH, and LH are stimulatory to estradiol (E2) and androstenedione (A4) production via interaction with 17-hydroxylase (CYP17A1) and aromatase (CYP19A1). Increased free IGF-1 in large follicles decreases FGF9 mRNA in GC, and this decreased FGF9 production causes a reduction in the FGF9 inhibition of $\mathrm{E} 2$ production by GC and A4 production by TC, causing an overall increase in E2 production by the dominant follicle. B.M. $=$ basement membrane; $\mathrm{OC}=$ oocyte. Color version available online.

cause a decrease in FGF9 mRNA in GC that allows for increased follicular E2 production, which then acts to inhibit FGF9 mRNA levels in TC, leading to an increase in androstenedione production providing addi- 
tional E2 precursor to GC (Figure 5). Further research will be required to verify this hypothesis.

Similar to what was found for GC, we noted a negative correlation between TC FGF9 mRNA and E2-to-P4 ratio in FFL. Also, TC of large EI follicles had greater abundance of FGF9 mRNA than large EA follicles, but only at $\mathrm{d} 3$ to 4 postovulation. Hormones that regulate TC FGF9 mRNA abundance have not been studied in any detail. Interestingly, factors (i.e., $\mathrm{TNF} \alpha$ and $\mathrm{WN}$ T3A) that inhibit FGF9 mRNA in GC (Schreiber and Spicer, 2012) and inhibit androstenedione production by TC (Spicer, 1998) were found to stimulate FGF9 mRNA in TC (Schreiber et al., 2012). We further hypothesized that IGF-1 may act in a feedback loop within TC, promoting FGF9 production to avoid premature differentiation of dominant follicles. Consistent with an opposing regulation of $F G F 9$ mRNA in TC versus GC is the general trend that FGF9 mRNA decreased in TC and increased in GC between d 3 to 4 and 5 to 6 in the present study. Results of the present study further extend our knowledge regarding hormones that regulate TC FGF9 mRNA, showing that androgens and, to a lesser extent, estrogens inhibit FGF9 mRNA in TC. This implies that a feedback loop may exist within the follicle: as more androgens and estrogens are produced, they feedback to inhibit TC FGF9 production and thus reduce the negative effect of FGF9 on follicular steroidogenesis (Figure 5). Further work will be required to elucidate the hormonal and developmental control of TC FGF9 mRNA.

In the present study, regardless of follicle size, $F G F 9$ mRNA abundance was greater in GC than in TC; this is in agreement with a previous study (Schreiber et al., 2012) and indicates that GC is the main cell type responsible for ovarian follicle production of FGF9. Also, abundance of FGF9 mRNA in GC varied more dramatically with follicle status than in TC, further suggesting a greater importance for GC in FGF9 production during folliculogenesis in cattle. Unfortunately, the 2 commercial ELISA kits available to measure FGF9 protein (i.e., bovine FGF9 ELISA, NovateinBio, Inc., Cambridge, MA; human FGF9 ELISA, R\&D Systems, Minneapolis, MN) did not have adequate sensitivity to detect FGF9 protein in FFL in the present study (L. J. Spicer and L. F. Schütz, unpublished data). Furthermore, attempts to use Western blotting to detect FGF9 in FFL were unsuccessful, most likely because of the small quantities of protein produced. Additional developmental work will be required to ascertain changes in FFL FGF9 protein levels during follicular growth and atresia.

In summary, FGF9 mRNA abundance in both GC and TC changed during development of dominant and subordinate follicles in cattle. Abundance of FGF9
mRNA was greater in GC than in TC, and the more dramatic change in FGF9 mRNA in GC versus TC indicated a greater importance for GC in ovarian FGF9 production during folliculogenesis in cattle. Dramatically less FGF9 mRNA abundance in dominant EA follicles than in EI subordinate follicles is consistent with what is expected from an antidifferentiation factor. We postulated, as a framework for future studies and based on the experimental data presented in this paper, that FGF9 may play a role in follicular growth and atresia in cattle.

\section{ACKNOWLEDGMENTS}

The authors thank Jeff Williams (Oklahoma State University, Stillwater) for his laboratory assistance; David Jones, Jeff Davis, and other members of the Oklahoma State University Dairy Cattle Center for care and management of the cows; the Oklahoma State University Microarray Core Facility and Oklahoma State University Recombinant DNA/Protein Resource Facility for use of equipment; and Creekstone Farms (Arkansas City, KS) for their generous donation of bovine ovaries. This work supported in part by the NICHD, National Institutes of Health (Bethesda, MD), through Agreement R15-HD-066302, and the Oklahoma State University Agricultural Experiment Station.

\section{REFERENCES}

Aad, P. Y., S. E. Echternkamp, and L. J. Spicer. 2013. Possible role of IGF2 receptors in regulating selection of 2 dominant follicles in cattle selected for twin ovulations and births. Domest. Anim. Endocrinol. 45:187-195.

Aad, P. Y., S. E. Echternkamp, D. D. Sypherd, N. B. Schreiber, and L. J. Spicer. 2012. The hedgehog system in ovarian follicles of cattle selected for twin ovulations and births: evidence of a link between the IGF and hedgehog systems. Biol. Reprod. 87:79.

Berisha, B., F. Sinowatz, and D. Schams. 2004. Expression and localization of fibroblast growth factor (FGF) family members during the final growth of bovine ovarian follicles. Mol. Reprod. Dev. $67: 162-171$.

Buratini, J., Jr., M. G. Pinto, A. C. Castilho, R. L. Amorim, I. C. Giometti, V. M. Portela, E. S. Nicola, and C. A. Price. 2007. Expression and function of fibroblast growth factor 10 and its receptor, fibroblast growth factor receptor $2 \mathrm{~B}$, in bovine follicles. Biol. Reprod. 77:743-750.

Chaves, R. N., M. H. de Matos, J. Buratini Jr., and J. R. de Figueiredo. 2012. The fibroblast growth factor family: Involvement in the regulation of folliculogenesis. Reprod. Fertil. Dev. 24:905-915.

Cho, J. H., T. Itoh, Y. Sendai, and H. Hoshi. 2008. Fibroblast growth factor 7 stimulates in vitro growth of oocytes originating from bovine early antral follicles. Mol. Reprod. Dev. 75:1736-1743.

Dentis, J. L., N. B. Schreiber, J. N. Gilliam, L. F. Schutz, and L. J. Spicer. 2016. Changes in brain ribonuclease (BRB) messenger RNA in granulosa cells (GCs) of dominant vs subordinate ovarian follicles of cattle and the regulation of $B R B$ gene expression in bovine GCs. Domest. Anim. Endocrinol. 55:32-40.

Drummond, A. E., M. Tellbach, M. Dyson, and J. K. Findlay. 2007. Fibroblast growth factor-9, a local regulator of ovarian function. Endocrinology 148:3711-3721. 
Evans, J. R., N. B. Schreiber, J. A. Williams, and L. J. Spicer. 2014. Effects of fibroblast growth factor 9 on steroidogenesis and control of FGFR2IIIc mRNA in porcine granulosa cells. J. Anim. Sci. 92:511-519.

Fortune, J. E., G. M. Rivera, A. C. Evans, and A. M. Turzillo. 2001. Differentiation of dominant versus subordinate follicles in cattle. Biol. Reprod. 65:648-654.

Gabler, C., A. Plath-Gabler, G. J. Killian, B. Berisha, and D. Schams. 2004. Expression pattern of fibroblast growth factor (FGF) and vascular endothelial growth factor (VEGF) system members in bovine corpus luteum endothelial cells during treatment with FGF-2, VEGF or oestradiol. Reprod. Domest. Anim. 39:321-327.

Grado-Ahuir, J. A., P. Y. Aad, and L. J. Spicer. 2011. New insights into the pathogenesis of cystic follicles in cattle: microarray analysis of gene expression in granulosa cells. J. Anim. Sci. 89:1769-1786.

Itoh, N., and D. M. Ornitz. 2011. Fibroblast growth factors: From molecular evolution to roles in development, metabolism and disease. J. Biochem. 149:121-130.

Jiang, Z., and C. A. Price. 2012. Differential actions of fibroblast growth factors on intracellular pathways and target gene expression in bovine ovarian granulosa cells. Reproduction 144:625-632.

Knecht, M., A. M. Brodie, and K. J. Catt. 1985. Aromatase inhibitors prevent granulosa cell differentiation: An obligatory role for estrogens in luteinizing hormone receptor expression. Endocrinology 117:1156-1161.

Lagaly, D. V., P. Y. Aad, J. A. Grado-Ahuir, L. B. Hulsey, and L. J. Spicer. 2008. Role of adiponectin in regulating ovarian theca and granulosa cell function. Mol. Cell. Endocrinol. 284:38-45.

LaPolt, P. S., M. Yamoto, M. Veljkovic, C. Sincich, T. Ny, A. Tsafriri, and A. J. Hsueh. 1990. Basic fibroblast growth factor induction of granulosa cell tissue-type plasminogen activator expression and oocyte maturation: potential role as a paracrine ovarian hormone. Endocrinology 127:2357-2363.

Livak, K. J., and T. D. Schmittgen. 2001. Analysis of relative gene expression data using real-time quantitative PCR and the 2(-Delta Delta C(T)). Methods 25:402-408.

Machado, M. F., V. M. Portela, C. A. Price, I. B. Costa, P. Ripamonte, R. L. Amorim, and J. Buratini Jr.. 2009. Regulation and action of fibroblast growth factor 17 in bovine follicles. J. Endocrinol. 202:347-353.

Ornitz, D. M., and N. Itoh. 2001. Fibroblast growth factors. Genome Biol. 2:REVIEWS3005.

Oron, G., B. Fisch, X. Y. Zhang, R. Gabbay-Benziv, G. Kessler-Icekson, H. Krissi, A. Ben-Haroush, A. Ao, and R. Abir. 2012. Fibroblast growth factor 10 in human ovaries. Reprod. Biomed. Online 25:396-401.

Ott, L. 1977. An Introduction to Statistical Methods and Data Analysis. Duxbury Press, North Scituate, MA.

Peluso, J. J., A. Pappalardo, and G. Fernandez. 2001. Basic fibroblast growth factor maintains calcium homeostasis and granulosa cell viability by stimulating calcium efflux via a PKC delta-dependent pathway. Endocrinology 142:4203-4211.

Portela, V. M., M. Machado, J. Buratini Jr., G. Zamberlam, R. L. Amorim, P. Goncalves, and C. A. Price. 2010. Expression and function of fibroblast growth factor 18 in the ovarian follicle in cattle. Biol. Reprod. 83:339-346.

Santiago, C. A., J. L. Voge, P. Y. Aad, D. T. Allen, D. R. Stein, J. R. Malayer, and L. J. Spicer. 2005. Pregnancy-associated plasma protein-A and insulin-like growth factor binding protein mRNAs in granulosa cells of dominant and subordinate follicles of preovulatory cattle. Domest. Anim. Endocrinol. 28:46-63.
Schams, D., V. Steinberg, M. Steffl, H. H. Meyer, and B. Berisha. 2009. Expression and possible role of fibroblast growth factor family members in porcine antral follicles during final maturation. Reproduction 138:141-149.

Schreiber, N. B., and L. J. Spicer. 2012. Effects of fibroblast growth factor 9 (FGF9) on steroidogenesis and gene expression and control of FGF9 mRNA in bovine granulosa cells. Endocrinology 153:4491-4501.

Schreiber, N. B., M. L. Totty, and L. J. Spicer. 2012. Expression and effect of fibroblast growth factor 9 in bovine theca cells. J. Endocrinol. 215:167-175.

Spicer, L. J. 1998. Tumor necrosis factor- $\alpha$ (TNF- $\alpha)$ inhibits steroidogenesis of bovine ovarian granulosa and thecal cells in vitro. Involvement of TNF- $\alpha$ receptors. Endocrine 8:109-115.

Spicer, L. J. 2004. Proteolytic degradation of insulin-like growth factor binding proteins by ovarian follicles: a control mechanism for selection of dominant follicles. Biol. Reprod. 70:1223-1230.

Spicer, L. J. 2005. Effects of estradiol on bovine thecal cell function in vitro: dependence on insulin and gonadotropins. J. Dairy Sci. $88: 2412-2421$

Spicer, L. J., M. A. Crowe, D. J. Prendiville, D. Goulding, and W. J. Enright. 1992. Systemic but not intraovarian concentrations of insulin-like growth factor-I are affected by short-term fasting. Biol. Reprod. 46:920-925.

Spicer, L. J., and J. M. Hammond. 1988. Comparative effects of androgens and catecholestrogens on progesterone production by porcine granulosa cells. Mol. Cell. Endocrinol. 56:211-217.

Spicer, L. J., C. A. Santiago, T. R. Davidson, T. S. Bridges, and C. S. Chamberlain. 2005. Follicular fluid concentrations of free insulinlike growth factor (IGF)-I during follicular development in mares. Domest. Anim. Endocrinol. 29:573-581.

Spicer, L. J., W. B. Tucker, and G. D. Adams. 1990. Insulin-like growth factor-I in dairy cows: relationships among energy balance, body condition, ovarian activity, and estrous behavior. J. Dairy Sci. 73:929-937.

Stewart, R. E., L. J. Spicer, T. D. Hamilton, and B. E. Keefer. 1995. Effects of insulin-like growth factor I and insulin on proliferation and on basal and luteinizing hormone-induced steroidogenesis of bovine thecal cells: involvement of glucose and receptors for insulin-like growth factor I and luteinizing hormone. J. Anim. Sci. 73:3719-3731.

Stewart, R. E., L. J. Spicer, T. D. Hamilton, B. E. Keefer, L. J. Dawson, G. L. Morgan, and S. E. Echternkamp. 1996. Levels of insulinlike growth factor (IGF) binding proteins, luteinizing hormone and IGF-I receptors, and steroids in dominant follicles during the first follicular wave in cattle exhibiting regular estrous cycles. Endocrinology 137:2842-2850.

Tilly, J. L., H. Billig, K. I. Kowalski, and A. J. Hsueh. 1992. Epidermal growth factor and basic fibroblast growth factor suppress the spontaneous onset of apoptosis in cultured rat ovarian granulosa cells and follicles by a tyrosine kinase-dependent mechanism. Mol. Endocrinol. 6:1942-1950.

Vernon, R. K., and L. J. Spicer. 1994. Effects of basic fibroblast growth factor and heparin on follicle-stimulating hormone-induced steroidogenesis by bovine granulosa cells. J. Anim. Sci. 72:2696-2702.

Woad, K. J., M. G. Hunter, G. E. Mann, M. Laird, A. J. Hammond, and R. S. Robinson. 2012. Fibroblast growth factor 2 is a key determinant of vascular sprouting during bovine luteal angiogenesis. Reproduction 143:35-43. 